\title{
Argumentações presentes nos conteúdos de matemática no livro didático da educação de jovens e adultos
}

\author{
Eloar Barreto Feitoza Sá ${ }^{1}$ \\ João Paulo Attie ${ }^{2}$
}

\begin{abstract}
Resumo
Investigamos os processos de argumentação presentes no livro didático recomendado pelo Programa Nacional do Livro Didático de 2014 à Educação de Jovens e Adultos, nível ensino médio. Procuramos evidenciar os tipos de argumentações existentes nas três unidades de conteúdos matemáticos do referido material didático. Para tanto, adotamos o entendimento de Freitas (2009) sobre livro didático e as definições atribuídas por Sales (2010) e Attie (2016), a partir de Balacheff (1988), às categorias de argumentação, explicativa e justificativa. Como resultado, apontamos que apesar de termos identificado as duas categorias nas unidades analisadas e considerarmos a argumentação justificativa essencial ao raciocínio voltado a uma formação crítica e cidadã, houve predominância da categoria explicativa.

Palavras-chave: Argumentação Matemática; Livro Didático; Ensino de Jovens e Adultos; Ensino Médio.
\end{abstract}

\section{Arguments present in the mathematics content in the textbook of youth and adult education}

\section{Abstract}

We researched the argumentation processes present in the textbook recommended by the 2014 National Textbook Program for Youth and Adult Education, high school level. Our objective was to highlight the types of arguments that exist in the three units of mathematical contained in the didatic material. To this aim, we adopted Freitas (2009) understanding of textbooks and the definitions attributed by Sales (2010) and Attie (2016), from Balacheff (1988), to the categories of argumentation, explanative and justificative. As a result, we pointed out that, although we have identified the two categories in the units analyzed and we consider the justificative argumentation essential to reasoning aimed at a critical and citizen formation, there was a predominance of the explanative category.

Keywords: Mathematics Argumentation; Textbook; Education for Youth and Adults; High School.

\section{Introdução}

Apesar de esforços de professores e educadores matemáticos no sentido da superação de um ensino tecnicista/formalista na disciplina, o que as pesquisas vêm apontando é ainda a predominância dessa modalidade na sala de aula (UTSUMI; LIMA, 2008; CARRIÃO, 2008; CORDEIRO; OLIVEIRA, 2015; ATTIE, 2016). O objetivo fundamental de um ensino tecnicista, em relação à matemática, é conseguir que o aluno utilize corretamente fórmulas e algoritmos, sem

\footnotetext{
${ }^{1}$ Universidade Federal de Sergipe, São Cristóvão, luarohaio@hotmail.com

2 Universidade Federal de Sergipe, São Cristóvão, jpattie@mat.ufs.br
} 
necessariamente compreender o contexto de suas aplicações ou a fundamentação lógica que garante a validade dos mesmos. No ensino formalista, ao menos, a fundamentação lógica se faz necessária (FIORENTINI, 1995). Entretanto, neste caso, o conhecimento matemático se encontra desprovido de outra justificativa que não o próprio desenvolvimento interno da matemática.

Em relação a essas duas tendências de ensino, apontadas por Fiorentini (1995), consideramos que, se desejamos formar cidadãos críticos, reflexivos e investigativos a respeito do mundo que os cerca, o ensino de matemática deve fazer mais sentido (que não o internalista) e favorecer a promoção da cidadania e de um olhar crítico-reflexivo para atuação em sociedade (PIRES, 2008; POMPEU, 2013). Estes aspectos nos parecem ainda mais importantes em se tratando de estudantes mais velhos, com uma história de vida e experiências, por vezes, associadas ao mercado de trabalho.

Nesse contexto, consideramos que a mera transmissão de conteúdos (ainda que justificados), centrada em um treinamento de técnicas de resolução de algoritmos, não contribui para uma formação crítica, já que se fundamenta em habilidades sem características reflexivas, como a memorização e a repetição. A necessidade de uma efetiva compreensão do processo que justifica os algoritmos e a articulação do conhecimento escolar com o cotidiano pode proporcionar a utilização da matemática como uma poderosa ferramenta para o desenvolvimento daquilo que é essencial à formação de um indivíduo com mais autonomia: o raciocínio. Uma vez que também é produto desse raciocínio, o conhecimento matemático deve ter sentido e significado para o ser humano (POMPEU, 2013).

Dessa forma, defendemos firmemente a posição de que o ensino de matemática deve ser voltado à compreensão da lógica que justifica os procedimentos e fórmulas, e não à mera memorização dos mesmos, o que parece ser o oposto do que se tem praticado, ao menos nos livros didáticos, pois "os mesmos possuem, predominantemente, ou uma falta de argumentos convincentes sobre a questão, ou uma pressa demasiada em apresentar o algoritmo, revelando a preferência pelo ensino do procedimento, em detrimento da compreensão do processo" (ATTIE, 2016, p.2268).

Assim, em relação à compreensão do que está por trás dos algoritmos, ponderamos que tal entendimento requer respostas às dúvidas dos alunos. Respostas estas que sejam 
propiciadas por argumentações que justifiquem a validade de determinado método/procedimento adotado, por exemplo, na resolução de um problema.

Diante dessas considerações, e também da importância do livro didático para o docente, pois este recurso pode ser considerado a "ferramenta principal na preparação de suas aulas" (BITTENCOURT, 1993; FREITAG et al., 1997) e, além disso, por ser um recurso que reúne os conteúdos disciplinares podendo contribuir para o desenvolvimento de práticas argumentativas, nos propusemos a identificar as argumentações presentes nas unidades de conteúdos matemáticos do livro didático da Educação de Jovens e Adultos (EJA), utilizado nas etapas correspondentes ao Ensino Médio. As argumentações consideradas em nosso exame foram de dois tipos: justificativas e explicativas, conforme definição apresentada na próxima seção. O livro em questão corresponde ao que fora aprovado no Programa Nacional do Livro Didático de 2014 (PNLD-2014), mas que permaneceu em circulação nos anos seguintes, até a data deste trabalho pelo menos. O exame realizado em um único livro não foi uma opção nossa, mas decorreu do fato de que o PNLD 2014 voltado à EJA aprovou apenas uma coleção.

Nas próximas seções procuramos trazer apontamentos sobre argumentação matemática, livro didático e EJA, enquanto modalidade de ensino à qual se destina o livro que examinamos. Em seguida, descrevemos brevemente a metodologia da pesquisa, as unidades de conteúdos matemáticos examinadas e as argumentações nelas encontradas.

\section{Argumentação matemática}

A habilidade de argumentar é, por vezes, associada ao desenvolvimento da criticidade, uma vez que ela favorece o pensamento reflexivo, a produção do conhecimento e, por conseguinte, o processo de aprendizagem. Assim, "argumentação, reflexão e construção do conhecimento são processos estreitamente relacionados" (LEITÃO, 2011, p.13).

Considerando-a como a expressão do raciocínio, ela tem relevante relação com habilidades matemáticas a serem desenvolvidas em ambiente escolar. Em Educação Matemática, nos fundamentamos na definição inicialmente proposta por Balacheff (1988), na qual a argumentação pode ser entendida como um processo em que são produzidas justificativas ou mesmo explicações. 
Embora pareça incoerente a afirmação de que uma explicação também corresponde a uma argumentação, consideramos que uma argumentação pode ser "ação de fazer ou mostrar como se faz e é ação de justificar porque se faz" (SALES, 2010, p.29, grifo do autor). Assim,

a partir da perspectiva de Balacheff (1988), enquanto a explicação supõe um discurso com o objetivo de tornar inteligível uma proposição ou um resultado, o termo justificativa compreende uma exposição das razões que os legitimam. Nesse contexto, chegamos [...] aos conceitos de "argumentação explicativa" e "argumentação justificativa". Em termos gerais, podemos dizer que, enquanto a argumentação explicativa é utilizada com a finalidade de apenas esclarecer, a argumentação justificativa tem o objetivo não somente de elucidar, mas de convencer (ATTIE, 2016, p.2262).

Dessa forma, em relação ao ensino de matemática, a argumentação explicativa está imbricada ao uso de fórmulas e técnicas, e facilmente encontramos respostas do tipo "é por definição", para legitimar seu uso. Como deve ser evidente, o uso da argumentação explicativa é bastante frequente nas salas de aula, quando o docente apresenta o conteúdo sem contextualizações históricas ou sociais e/ou sem justificativas plausíveis para a utilização dessas fórmulas. À vista disso, seu intuito preza pela aplicabilidade dos algoritmos e não pela compreensão do processo envolvido por trás dos elementos empregados.

Em relação ao livro didático analisado, como o mesmo é destinado a estudantes da Educação de Jovens e Adultos, consideramos apropriado falarmos um pouco a respeito dessa modalidade de ensino.

\section{Educação de jovens e adultos no Brasil}

Garantir acesso à educação inclusive àqueles que não o tiveram em idade própria é, constitucionalmente, dever do Estado (BRASIL, 1988). Dessa forma, assim como o livro didático, a educação destinada a jovens e adultos enquanto modalidade de ensino também constitui uma política educacional. A Educação de Jovens e Adultos que, antes da década de 1980, era conhecida como Ensino Supletivo (ALMEIDA; CORSO, 2015), é uma modalidade de ensino da educação básica com características específicas e à qual devem se estender as Diretrizes Curriculares Nacionais de cada nível de ensino (fundamental e médio) a que corresponder (BRASIL, 2000). 
Suas principais características são a redução da carga horária, quando comparada ao ensino regular, e o público a que se destina: pessoas com idade superior à idade oficialmente estabelecida para o ensino fundamental e/ou médio, sendo, portanto, jovens e adultos, como consta na denominação recebida pela modalidade (ALMEIDA; CORSO, 2015).

Sob esse aspecto, a Lei no 9394/96 aponta que a EJA deve abranger propostas pedagógicas específicas que atentem às características, interesses, condições de vida e de trabalho do público a que se destina. Respeitando princípios do ensino estabelecidos nessa lei, isso corresponderia à "valorização da experiência extraescolar" e também à "vinculação entre a educação escolar, o trabalho e as práticas sociais" (BRASIL, 1996).

Vale ressaltar que essa lei preceitua ainda, em consonância com a Constituição Federal de 1988, que é do Estado o dever de prover a educação básica, em todas as suas etapas, com material didático, além de outros elementos fundamentais ao funcionamento do ensino com o mínimo de qualidade (BRASIL, 1988). Dentro do primeiro aspecto (material didático), temos o livro didático como peça fundamental. E para a EJA, certamente, o cuidado com a elaboração desse material deve partir das peculiaridades dessa modalidade, sendo necessários abordagem, metodologia e materiais coerentes com a realidade dos jovens e adultos que ingressam na mesma.

Assim, em concordância com as especificidades dos estudantes da EJA, é apontado pela LDB no 9394/96 que a educação escolar deve voltar-se ao trabalho e às práticas sociais. Além disso, um dos princípios apresentados nessa lei, como base para o ensino, é o estabelecimento de um padrão de qualidade. Por conseguinte, ao assumir a responsabilidade pela compra e distribuição dos livros didáticos, o Programa Nacional do Livro Didático (PNLD) tem por objetivo tanto o provimento, quanto atuar na avaliação desse material didático a partir de aspectos considerados qualificadores.

\section{Livro didático: o programa e seu alcance e os dados do livro examinado}

Importante recurso no processo de ensino-aprendizagem, o livro didático reúne conteúdos disciplinares de forma sistemática e didática. De maneira mais concreta, podemos dizer que o livro didático é 
um artefato impresso em papel, que veicula imagens e textos em formato linear e seqüencial, planejado, organizado e produzido especificamente para uso em situações didáticas, envolvendo predominantemente alunos e professores, e que tem a função de transmitir saberes circunscritos a uma disciplina escolar (FREITAS, 2009, p.03).

O fato de estar inserido em políticas públicas propicia ao livro didático uma ampla difusão por todo o território nacional. Com a criação do Instituto Nacional do Livro, na década de 1930, os livros didáticos começaram a ter uma visibilidade política que culminou na grande circulação desse material atualmente.

Desde esse momento histórico, foram promulgadas leis e normativas a respeito da produção e distribuição gratuita desse recurso didático. Como exemplos temos o Decreto-lei 1.006, de 30 de dezembro de 1939, que estabelecia "as condições de produção, exportação e utilização do livro didático"; o Decreto-lei 8.460, de 26 de dezembro de 1945 que consolidava "a legislação sobre as condições de produção, importação e utilização do livro didático." e o Decreto no 59.355, de 04 de outubro de 1966 que Instituiu "Ministério da Educação e Cultura a Comissão do Livro Técnico e do Livro Didático (COLTED)" (BRASIL, 1939/1945/1966).

Na década de 1970 foi criado um programa referente ao livro didático voltado apenas para o ensino fundamental. Este programa, em 1985, passou a ser denominado Programa Nacional do Livro Didático (PNLD), denominação mantida até os dias atuais.

O programa abrange uma sistemática de avaliação, produção e distribuição para provimento desse material com determinado nível de qualidade. No decorrer dos anos, o PNLD começou a ampliar o atendimento às escolas públicas beneficiando, com livros didáticos, também o ensino médio regular, a partir de 2008, e a EJA que, por sua vez, ingressou no programa, em 2011 (nível fundamental) e em 2014 (nível ensino médio).

Nos ensinos fundamental e médio, os livros didáticos de língua portuguesa, matemática, ciências, história e geografia são reutilizados dentro de um ciclo de três anos, ou seja, a cada final de ano letivo devem ser devolvidos para serem redistribuídos a outros alunos. No caso da EJA, todos os livros didáticos destinados a esta modalidade de ensino são consumíveis, ou seja, uma vez distribuídos, os alunos e educadores "passam a ter sua guarda definitiva, sem necessidade de devolução ao final de cada período letivo" (BRASIL, 2009, p.03).

A princípio, a escolha das coleções e a distribuição dos livros didáticos ocorrem a cada 
três anos, podendo haver reposição anual no decorrer desse período, conforme o número de matrículas ocorridas na instituição de ensino. Contudo, em 2017 (para 2018) e em 2019, não houve novo processo de avaliação para a escolha de livros didáticos destinados à EJA. Segundo comunicado do FNDE, isto ocorreu devido à realização de "revisão de marcos legais da educação nacional com posterior necessidade de atualização de livros didáticos" (BRASIL, 2017; BRASIL, 2019), sendo mantida a distribuição de livros aprovados no último PNLD EJA, o de 2014.

Apesar das referidas alterações legais e também da aprovação recente da Base Nacional Comum Curricular (BNCC) que conduzem a mudanças curriculares, não exploramos esses aspectos no presente artigo tendo em vista que o livro analisado, que permanece em circulação mediante decisão tomada pelo FNDE com a justificativa citada, foi produzido anteriormente a tais marcos. Assim, ponderamos ser conveniente apontarmos a exigência presente no edital de convocação a partir do qual a coleção foi inscrita no programa de 2014. Isto posto, reforçamos a importância desta análise considerando que o livro permanece em circulação e que a presença da argumentação, requerida naquele momento, tem recebido crescente atenção em pesquisas nos últimos anos (REGINALDO, 2012; GIL, 2013; MONTEIRO, 2013; CARMO, 2015; RODRIGUES, 2018) e na própria BNCC, documento que tem mobilizado discussões especialmente por não conter uma indicação direta, ou melhor, um direcionamento específico para a Educação de Jovens e Adultos.

No PNLD EJA 2014, segundo consta no Guia do Livro Didático (BRASIL, 2014), foram inscritas cinco coleções destinadas ao Ensino Médio, sendo que somente uma foi aprovada. Portanto, há apenas uma coleção em vigência, a Coleção "Viver, Aprender". Uma vez que esta coleção continua em circulação para uso nas escolas, é dela o livro que utilizamos com o propósito de evidenciar os tipos de argumentação presentes nos conteúdos matemáticos.

Convém ressaltarmos que, no edital de convocação para inscrição de livros e coleções no PNLD EJA 2014, a capacidade de argumentação é apresentada entre os princípios e critérios para a avaliação do componente curricular Matemática. No referido documento consta que o ensino de matemática "deve capacitar os estudantes para compreender e transmitir ideias matemáticas, por escrito ou oralmente, desenvolvendo a capacidade de argumentação" (BRASIL, 2012, p.94).

Além disso, dentre os critérios eliminatórios de livros e/ou coleções inscritas no 
programa, está a necessidade de haver aspectos que possibilitem "o desenvolvimento, pelo aluno, de competências cognitivas básicas, como: observação, compreensão, argumentação, organização, análise, síntese, comunicação de ideias matemáticas, memorização", bem como, de não existir na obra "erro ou indução a erro em conceitos, argumentação e procedimentos matemáticos" (BRASIL, 2012, p.95). Ressalta-se ainda entre tais critérios, o cuidado em evitar a indução ao "trabalho mecânico" no uso de conceitos matemáticos para a resolução de problemas.

Embora não haja, no referido edital de convocação, uma definição específica para a argumentação, percebemos uma atenção voltada à importância dessa competência na abordagem de conteúdos matemáticos. É possível que a definição considerada neste documento esteja próxima à ideia sobre argumentação apontada nos Parâmetros Curriculares Nacionais (PCN), de 1998: “a argumentação está fortemente vinculada à capacidade de justificar uma afirmação e, para tanto, é importante produzir alguma explicação, bem como justificá-la" (BRASIL, 1998, p.70).

Logo, mesmo sem um esclarecimento quanto à definição especificamente no documento convocatório, este ressalta a argumentação como critério avaliativo dos livros didáticos de matemática. Cientes dessa importância, partimos para o que nos propomos e, assim, a seguir descrevemos como estão organizadas as unidades de matemática do volume Ciência da Natureza e Matemática, da coleção "Viver, Aprender" que foi a única coleção aprovada. E, na sequência, evidenciamos as argumentações explicativas e justificativas presentes na obra.

\section{Sobre o volume Ciências da Natureza e Matemática da coleção "Viver, Aprender", de Scrivano et al. (2013)}

A coleção didática destinada ao ensino médio na modalidade de EJA está organizada em três volumes com as seguintes denominações: Linguagem e Códigos, Ciências da Natureza e Matemática e Ciências Humanas. O segundo volume abrange os componentes curriculares Física, Química e Biologia intercalados e Matemática em uma unidade distinta. Essa composição não foi obrigatória, pois o edital indicou a viabilidade de inscrição de um número maior de volumes (um para cada componente curricular ou mesmo de três a seis volumes temáticos). 
Contudo, a única coleção aprovada está conforme indicado no início deste parágrafo. Além disso, há uma organização pelo que foi chamado de etapas, ou seja, os conteúdos correspondentes à primeira série do Ensino Médio equivalem ao bloco Etapa 1, os correspondentes à segunda série são do bloco Etapa 2 e os da Etapa 3 são os conteúdos referentes à terceira série.

A referida coleção possui caixas de texto com sugestões para debate, pesquisa, reflexão, bem como para aprofundamento dos conteúdos com indicação de filmes, livros e sites relacionados.

O componente Matemática, em unidade distinta dos demais componentes curriculares, possui seis capítulos, distribuídos em 73 páginas, na unidade destinada à primeira etapa intitulada Matemática e Vida Cotidiana, conforme quadro 1.

Quadro 1: Conteúdos abordados na primeira unidade de matemática do livro Viver, Aprender (EJA-Ensino Médio).

\begin{tabular}{|c|l|}
\hline Título do capítulo & \multicolumn{1}{c|}{ Conteúdo abordado } \\
\hline Letras e Números & $\begin{array}{l}\text { Uma introdução à álgebra, noção de proporcionalidade e regras } \\
\text { de três (simples e composta). }\end{array}$ \\
\hline Pagamentos e cia. & $\begin{array}{l}\text { Noções básicas de matemática financeira: operações com } \\
\text { números racionais, porcentagem, significado de juros. }\end{array}$ \\
\hline $\begin{array}{c}\text { Cidades, } \\
\text { planejamento, } \\
\text { ocupações }\end{array}$ & $\begin{array}{l}\text { Aspectos sobre localização geográfica para chegar à noção de } \\
\text { retas paralelas, concorrentes e coincidentes, de plano cartesiano, } \\
\text { ângulos, áreas, perímetros e unidades de medida. }\end{array}$ \\
\hline $\begin{array}{c}\text { Dependência entre } \\
\text { grandezas: funções }\end{array}$ & Funções polinomiais do 10 e 20 graus e funções exponenciais. \\
\hline $\begin{array}{c}\text { Fórmulas e direitos } \\
\text { Regularidades que conduzem a fórmulas e novamente elementos } \\
\text { un economia como sistema monetário, salário, tributos, juros. É } \\
\text { um capitulo mais centrado em discussão sobre situações que } \\
\text { envolvem essa temática. }\end{array}$ \\
\hline $\begin{array}{c}\text { Pitágoras, seu teorema } \\
\text { e o número irracional }\end{array}$ & $\begin{array}{l}\text { O teorema de Pitágoras, conjuntos numéricos, arredondamento } \\
\text { de números. }\end{array}$ \\
\hline
\end{tabular}

Fonte: autores deste artigo,2019.

A unidade da Etapa 2, denominada A Matemática Resolvendo Problemas, é composta por quatro capítulos (quadro 2) distribuídos em 53 páginas. 
Quadro 2: Conteúdos abordados na segunda unidade de matemática do livro Viver, Aprender (EJA-Ensino Médio).

\begin{tabular}{|c|l|}
\hline Título do capítulo & \multicolumn{1}{|c|}{ Conteúdo abordado } \\
\hline Você, a mídia e a Matemática & $\begin{array}{l}\text { Tratamento de dados com uso de ferramentas como } \\
\text { tabelas e gráfico. }\end{array}$ \\
\hline $\begin{array}{c}\text { Sistemas de numeração, de } \\
\text { medidas e problemas de } \\
\text { contagem }\end{array}$ & $\begin{array}{l}\text { Sistema binário, sistema de numeração decimal, medidas } \\
\text { de tempo, de ângulos, problemas de contagem. }\end{array}$ \\
\hline $\begin{array}{c}\text { Sistemas de equações, } \\
\text { elementos de geometria } \\
\text { analítica e probabilidade }\end{array}$ & $\begin{array}{l}\text { Sistema de equações solucionado pelo método da } \\
\text { substituição, geometria analítica (mais especificamente } \\
\text { equação da reta) e probabilidade. }\end{array}$ \\
\hline $\begin{array}{c}\text { Congruência, semelhança e } \\
\text { o teorema de Tales }\end{array}$ & Congruência e semelhança geométrica, Teorema de Tales. \\
\hline
\end{tabular}

Fonte: autores deste artigo, 2019.

Na terceira e última seção correspondente à Etapa 3, sob o título Formas e Medidas, constam seis capítulos, em 62 páginas (ver quadro 3).

Quadro 3: Conteúdos abordados na terceira unidade de matemática do livro Viver, Aprender (EJA-Ensino Médio).

\begin{tabular}{|c|l|}
\hline Título do capítulo & \multicolumn{1}{c|}{ Conteúdo abordado } \\
\hline Forma para que te quero? & Sólidosgeométricos. \\
\hline $\begin{array}{c}\text { Trigonometria no triângulo retângulo e } \\
\text { outros elementos de geometria } \\
\text { analítica }\end{array}$ & $\begin{array}{l}\text { Uma introdução à trigonometria e novamente a } \\
\text { equação reduzida de reta. }\end{array}$ \\
\hline $\begin{array}{c}\text { Comprimento e área de figuras com } \\
\text { componentes circulares }\end{array}$ & $\begin{array}{l}\text { Comprimento e área de figuras e sólidos com } \\
\text { formas circulares. }\end{array}$ \\
\hline $\begin{array}{c}\text { Volumes e alguns indicadores } \\
\text { Importantes }\end{array}$ & Volumes. \\
\hline $\begin{array}{c}\text { Resolução de problemas, progressões e } \\
\text { uma nova equação }\end{array}$ & $\begin{array}{l}\text { Problemas, progressões aritmética e geométrica, } \\
\text { equações exponenciais. }\end{array}$ \\
\hline $\begin{array}{c}\text { Inequações, representações gráficase } \\
\text { elementos de geometria analítica }\end{array}$ & $\begin{array}{l}\text { Inequações, representação gráfica de soluções de } \\
\text { equações e inequações e elementos de geometria } \\
\text { analítica (ponto, segmento, distância entre pontos. }\end{array}$ \\
\hline
\end{tabular}

Fonte: autores deste artigo, 2019.

É perceptível a redução nos conteúdos em relação ao ensino médio regular, sendo que alguns conteúdos não foram abordados, a exemplo de matrizes. Aqueles que se encontram no livro apresentam-se, em sua maioria, de maneira sintetizada, com apenas características básicas e, eventualmente, uma breve associação a situações do cotidiano. 
A esse respeito, a exigência presente na legislação se concentra no mínimo de componentes curriculares, não havendo um currículo padrão para a modalidade EJA (BRASIL, 2014). Segundo a Resolução CNE/CEB no 01, de 05 de julho de 2000, "os conteúdos e as competências assinalados nas áreas definidas nas diretrizes curriculares nacionais do ensino médio serão explicitados pelos respectivos sistemas [de ensino], observadas as especificidades da educação de jovens e adultos" (BRASIL, 2000, p.03).

Essa é uma importante questão a se observar, contudo discutir o currículo e conteúdos disciplinares não é o nosso foco neste artigo. Nosso objetivo é evidenciar argumentações dos tipos justificativas e explicativas, presentes no livro examinado. Para tanto, consideramos as duas categorias elencadas por Sales (2010) e Attie (2016), a partir da perspectiva de Balacheff (1988):

1. Argumentações justificativas - aquelas que apresentam justificativas lógicas para os procedimentos ou fórmulas matemáticas.

2. Argumentações explicativas - aquelas que apenas indicam passos de procedimentos a serem adotados.

A partir dessas duas categorias, examinamos as três unidades de conteúdos matemáticos e o resultado,descrevemos a seguir.

\section{As unidades de Matemática e a presença de argumentações}

No Guia do Livro Didático, em relação ao componente curricular Matemática da Coleção Viver, Aprender, volume Ciência, Transformação e Cotidiano, a análise feita pelos avaliadores é colocada de maneira breve, apenas com características gerais. Eles relatam alguns pontos positivos como a presença de textos com temáticas políticas, econômicas e sociais em coerência com a realidade dos estudantes jovens e adultos. Ressaltam também fragilidades da obra. Segundo os avaliadores,

na proposta metodológica endereçada ao orientador, afirma-se que "um dos pontos altos na abordagem dos conteúdos é usar a metodologia de resolução de problemas". No entanto, não é o que se verifica na maior parte da obra, pois, ao apresentar situações-problema, logo se fornece sua solução sem sequer mencionar, ao leitor, os passos fundamentais adotados para a resolução

Periódico Horizontes - USF - Itatiba, SP - Brasil - e020044 
dos problemas propostos, tais como a identificação de variáveis, a interpretação detalhada do enunciado, a abstração, a operação e a validação (BRASIL, 2014, p.224).

Em relação à presença de argumentações na obra, ao verificarmos as três unidades de conteúdos matemáticos, identificamos algumas argumentações justificativas logo no início da primeira unidade. Esta começa com o capítulo que introduz aspectos algébricos. O capítulo intitulado "Letras e Números" é iniciado com um texto sobre simbologia seguido de outro sobre a linguagem algébrica. Mas é um pouco mais à frente, em meio aos exercícios, que encontramos uma argumentação justificativa quando são apresentados "os passos utilizados para resolver as equações [algébricas]" (SCRIVANO et al., 2013, p.114). São dados três exemplos, um com operação de adição, outro com multiplicação e o terceiro com as duas operações (figuras 1, 2 e 3). É apresentado o processo envolvido no conhecido "passa para o outro lado com sinal oposto" ou "se está multiplicando, passa dividindo". Nos exemplos, entretanto, os autores mostram que não se trata de "passar para o outro lado" e apresentam o processo completo e também o que chamaram de resolução simplificada (a que se costuma fazer usando a expressão "passa para o outro lado").

Nos exemplos, temos:

Figura 1: Resolução de equação com justificativas para procedimentos

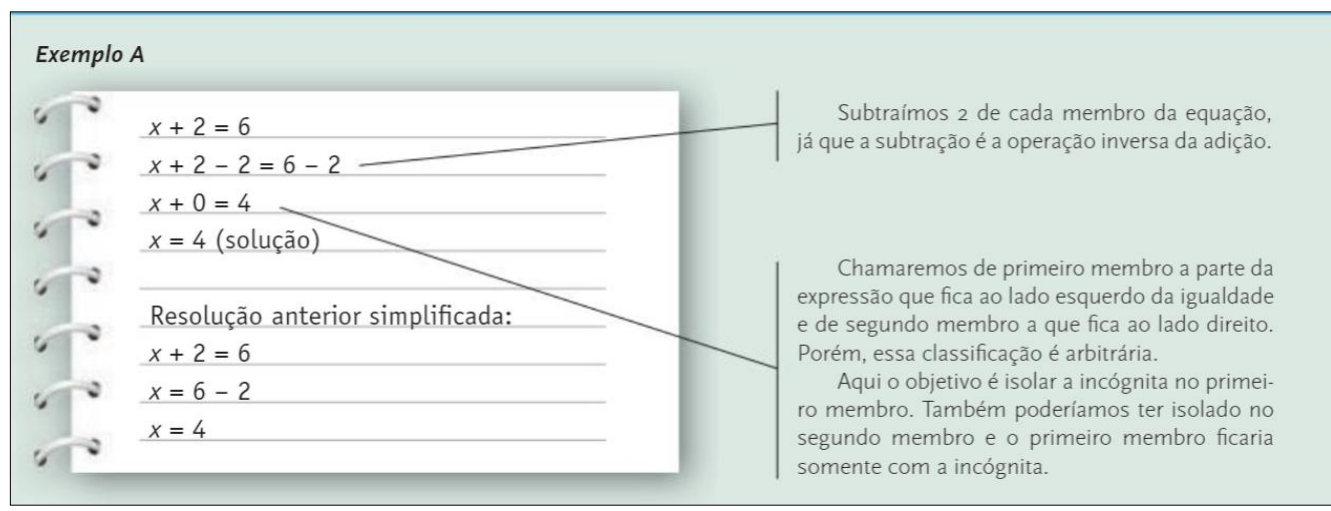

Fonte: Scrivano et al. (2013, p.114).

Ao lado, os autores esclarecem que "o objetivo é isolar a incógnita no primeiro membro". Eles complementam dizendo que "também poderíamos ter isolado no segundo 
membro e o primeiro membro ficaria somente com a incógnita" (SCRIVANO et al., 2013, p.114).

No segundo exemplo, em que há multiplicação na equação, eles procedem da seguinte forma:

Figura 2: Exemplo de solução de uma equação com fração usando justificativa para procedimentos

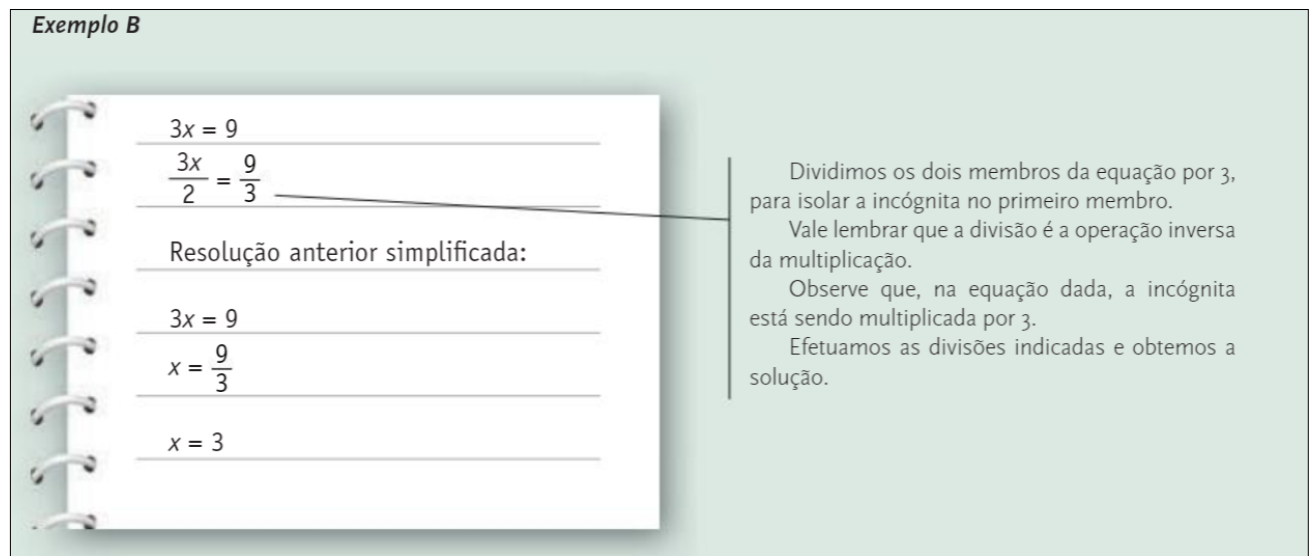

Fonte: Scrivano et al. (2013, p.114).

Embora tenham colocado, equivocadamente, o número 2 (dois) no denominador do primeiro membro da equação, os autores informam: "dividimos os dois membros da equação por 3, para isolar a incógnita no primeiro membro" (SCRIVANO et al., 2013, p.114) e, em seguida, apresentam a denominada solução simplificada.

No terceiro exemplo, eles seguem essa mesma linha de justificativa para o procedimento de resolução da equação algébrica dada, conforme figura 3. 
Figura 3: Exemplo de argumentação justificativa

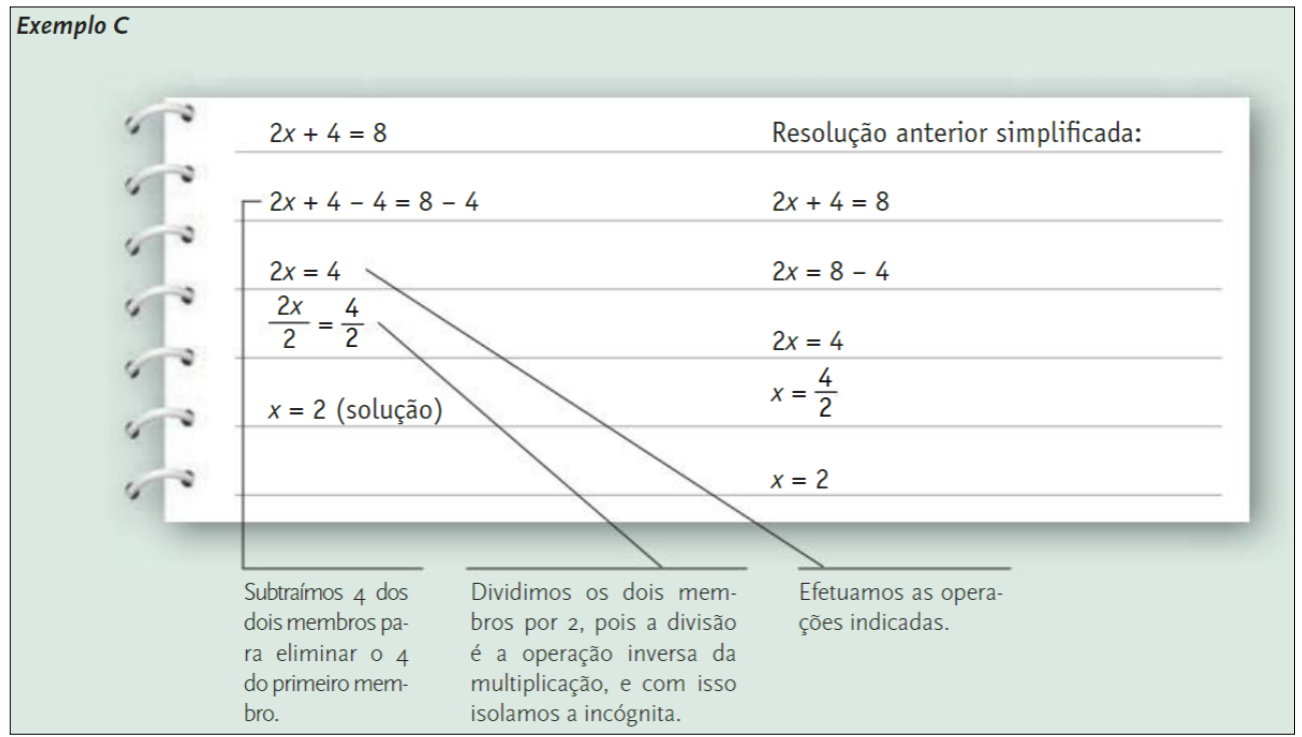

Fonte Scrivano et al. (2013, p.115).

\section{Ainda na unidade da etapa 1 , quando os autores falam de operações entre números} racionais, mais especificamente, divisão, eles justificam:

Figura 4: Exemplo referente à divisão entre números racionais

\section{E na divisão, como podemos fazer?}

Para a divisão de dois racionais não inteiros escritos na forma decimal, seria importante lembrar primeiro que, quando multiplicamos o dividendo e o divisor por um mesmo número (não nulo), o resultado da divisão (quociente) não se altera. Então, uma sugestão seria multiplicarmos o dividendo e o divisor por um mesmo número (uma potência de 10 convenientemente escolhida, ou seja, 10, 100, 1000 etc.), de tal maneira que se tornem inteiros e, em seguida, fazemos a divisão desses inteiros. Por exemplo, vamos dividir 3,3 por 0,55 . Para que os dois valores se tornem inteiros simultaneamente, devemos multiplicá-los por $100\left(10^{2}\right)$, dessa forma:

$$
\begin{aligned}
& 3,3 \times 100=330 \\
& 0,55 \times 100=55
\end{aligned}
$$

Dividimos então 330 por 55 , obtendo como quociente 6 .

Tal fato se justifica, já que a multiplicação da razão $\frac{33}{0,55}$ por $\frac{100}{100}$ equivale a $\frac{330}{55}$, pois $\frac{100}{100}$ é o mesmo que 1, elemento neutro da multiplicação. Assim, entende-se por que o resultado não se altera.

$$
\frac{33}{0,55} \times \frac{100}{100}
$$

Fonte: Scrivano et al. (2013, p.128). 
Novamente há uma falha gráfica-editorial (seria 3,3/0,55 ao invés de 33/0,55). Mas, quanto à argumentação, observa-se que, para a afirmação inicial, há a justificativa logo em seguida.

Mais adiante, no capítulo 3, os autores apresentam também a construção de fórmulas de áreas de figuras planas, iniciando pelo retângulo a partir da ideia de unidade de área (figura 5) e, seguindo para a área do quadrado. Em seguida, decompondo figuras, chegam às fórmulas de áreas do paralelogramo (figura 6), do trapézio, do triângulo e do losango.

Figura 5: Ilustração para unidades de área

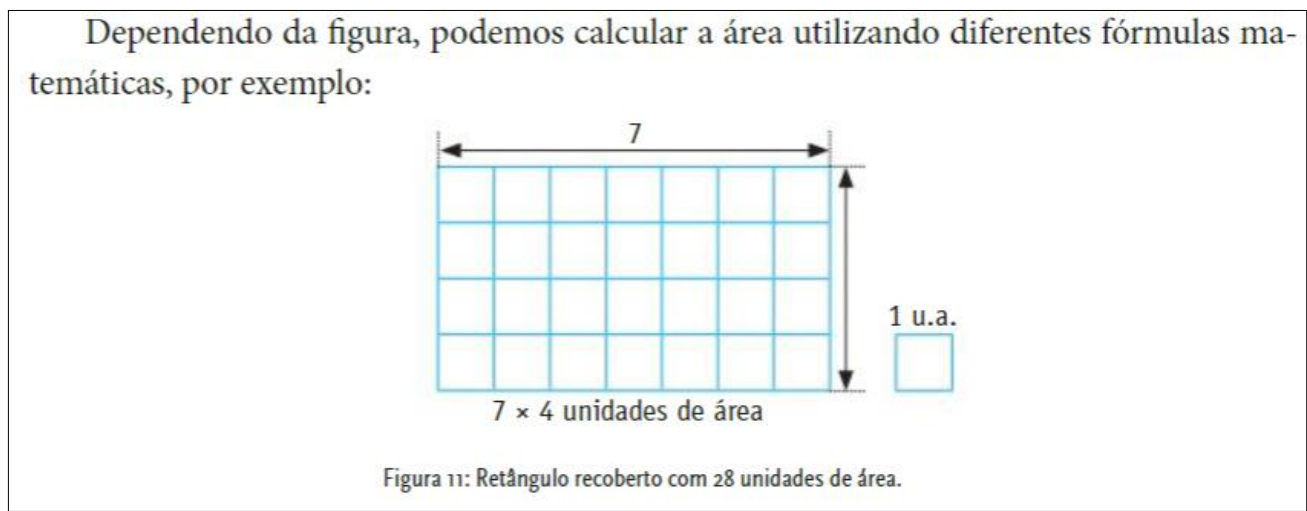

Fonte: Scrivano et al. (2013, p.143).

Figura 6: llustração para a área de um paralelogramo

Em um paralelogramo, por exemplo, podemos verificar de modo intuitivo que, ao "decompor suas partes" conforme alguns critérios, é possível compor um retângulo. Veja a figura 12:
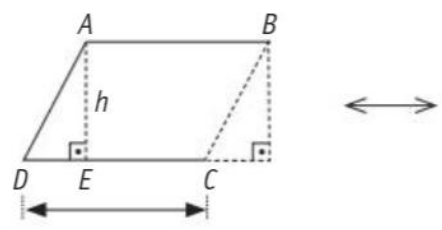

Segmento $D C$ de medida $b$

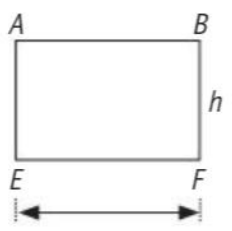

Segmento EF de medida $b$

Figura 12: Paralelogramo $A B C D E$ e retângulo $A B F E$.

Fonte: Scrivano et al. (2013, p.144).

Da forma como fizeram (as figuras 5 e 6 são apenas recortes da argumentação adotada pelas autores neste conteúdo matemático), as fórmulas não foram simplesmente dadas para aplicação, mas apresentadas como tendo uma origem, um porquê de ser aquela a ser usada 
para a correspondente figura geométrica. Segundo Sales (2010), a prática argumentativa é tida nos PCNs como favorável ao desenvolvimento da habilidade da demonstração em matemática. Esta, segundo ele, é um caso particular de argumentação e prova caracterizada pela aceitação por especialistas, podendo ou não ser alcançada a partir de recursos lógicos (verbais, gráficos etc.).

Ainda em relação à argumentação justificativa, identificamos também que o sentido de função é apontado antes da definição padrão e na abordagem feita sobre as funções exponenciais, a ideia de juros compostos é apresentada demonstrando-se o montante que se tem a cada período em que incide esse tipo de juro, de maneira que se chega à fórmula geral. Não deixa de ser um argumento justificativo, contudo, consideramos que a forma como foi feita a apresentação poderia ter sido mais dinâmica.

Figura 7: Demonstração para obtenção da fórmula geral de juros compostos

Seria possível estabelecer uma fórmula para calcular o montante obtido a juros compostos?

Consideremos um capital $C$, uma taxa de juros $i$ e calculemos o montante obtido a juros compostos, após $n$ períodos de tempo (expresso na unidade de tempo da taxa).

- Montante após 1 período:

$$
M_{1}=C+C \times i=C \times(1+i)
$$

- Montante após 2 períodos:

$$
M_{2}=M_{1}+M_{1} \times i=M_{1} \times(1+i)=C \times(1+i) \times(1+i)=C \times(1+i)^{2}
$$

- Montante após 3 períodos:

$$
M_{3}=M_{2}+M_{2} \times \mathrm{i}=M_{2} \times(1+i)=C \times(1+i)^{2} \times(1+i)=C \times(1+i)^{3}
$$

E assim por diante..

$$
\begin{gathered}
M=C \times[(1+i) \times(1+i) \times \ldots \times(1+i)] \\
\ldots n \text { vezes } \ldots
\end{gathered}
$$

É fácil perceber, por generalização, que após $n$ períodos o montante será dado por: $M=C \times(1+i)^{n}$

Fonte: Scrivano et al. (2013, p.160).

No caso do Teorema de Pitágoras, este foi enunciado, os termos principais nele presentes foram apontados e, inclusive, os autores procuraram dizer o sentido da expressão "quadrado da hipotenusa". Eles fizeram uso de uma ilustração (figura 8) para indicar, mais 
adiante, a maneira algébrica de apresentação do referido teorema. Com tal ilustração, os autores apontaram uma relação com quadrados formados sobre a hipotenusa e cada um dos catetos de um triângulo retângulo, contudo, não a exploraram tal qual uma justificativa.

Figura 8: Apresentação do Teorema de Pitágoras

Observe o desenho.

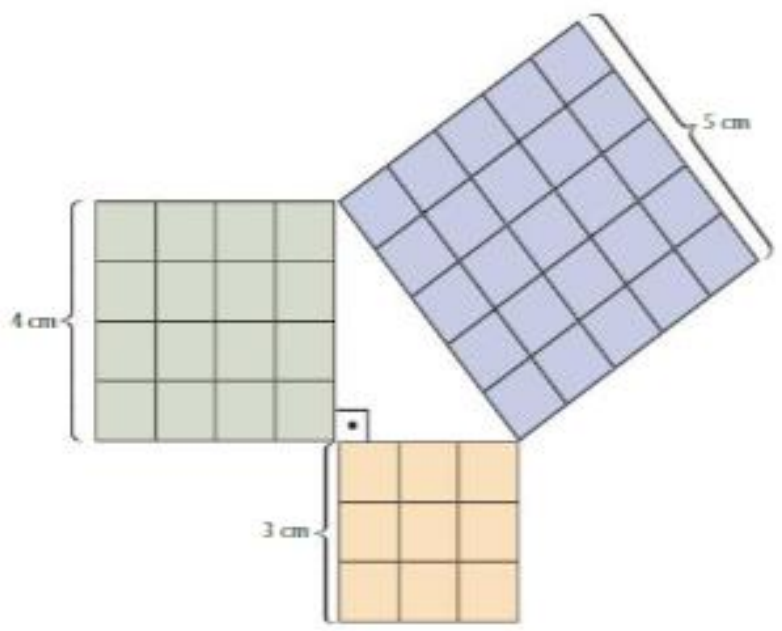

O triângulo retângulo está no centro da figura e sobre a hipotenusa foi construido um quadrado de lado medindo $5 \mathrm{~cm}$; sobre um dos catetos foi construido um quadrado de lado medindo $3 \mathrm{~cm}$ e, sobre o outro cateto, um outro quadrado de lado medindo $4 \mathrm{~cm}$. Verificando a relação proposta pelo Teorema de Pitágoras, observa-se que:

$$
\begin{aligned}
& 5^{2}-4^{2}+3^{2} \\
& 25-16+9
\end{aligned}
$$

Não parece dificil entender o significado do Teorema de Pitágoras. Em resumo, o teorema afirma que a área do quadrado formado sobre a hipotenusa equivale à soma das áreas dos dois quadrados formados sobre os catetos.

Fonte: Scrivano et al. (2013, p.172).

Seguindo para a unidade da etapa 3, observamos que os autores também indicam por que o comprimento de uma circunferência é dado por $c=2 . \pi . r$, usando a relação entre comprimento e diâmetro da circunferência enquanto correspondente a $\pi$. Todavia, a justificativa seria melhor construída se eles partissem do texto inicial, em que sugerem que o aluno experimente medir uma circunferência e seu diâmetro. Desse texto, poderiam trilhar o caminho que conduz à fórmula. Os autores sugerem a tomada de medida de uma roda de bicicleta, mas poderiam sugerir quaisquer outros objetos circulares, os quais poderiam até 
mesmo ser usados durante a aula. Com isso, se chegaria à relação que temos como o número $\pi$. Mas ao invés disso, eles afirmam apenas que:

Figura 9: Afirmativa sobre a relação entre comprimento e diâmetro de uma circunferência

Por meio de métodos matemáticos mais sofisticados, prova-se que $\frac{c}{d}=\pi$.

Fonte: Scrivano et al. (2013, p.468).

Ainda com a circunferência, a fórmula de sua área é apenas apresentada e seu uso exemplificado. Não há qualquer justificativa. Trata-se, portanto, de uma argumentação explicativa, ou seja, argumentação que apenas descreve, mostra como se faz e não o porquê de se fazer determinado procedimento.

Em relação às argumentações explicativas, elas estão bastante presentes nos capítulos de conteúdos matemático do livro fonte deste artigo. Como exemplo inicial para esse tipo de argumentação, temos o capítulo que trata de ângulos. Nele, os autores informam que uma volta completa é igual a $360^{\circ}$, mas não informam o porquê (figura 10).

Figura 10: Afirmação sem justificativa sobre ângulo

O ponteiro maior do relógio, ao percorrer os 60 minutos, deu uma volta completa, correspondente ao intervalo entre 13 e 14 horas. Nesse caso, determinou o que podemos chamar de ângulo de giro, ou seja, percorreu $360^{\circ}$.

Fonte: Scrivano et al. (2013, p.138)

Outro exemplo pode ser visto quando na unidade da etapa 1, abordando regra de três composta a partir de um problema e os passos para resolvê-lo, os autores informam, conforme indicado na figura 11, que "a incógnita x será obtida da forma sugerida no esquema a seguir" (SCRIVANO et al., 2013, p.120), sem qualquer justificativa quanto à ordem das frações ou ao motivo da fração x/6 estar após a igualdade etc. 
Figura 11: Forma de obtenção de uma incógnita

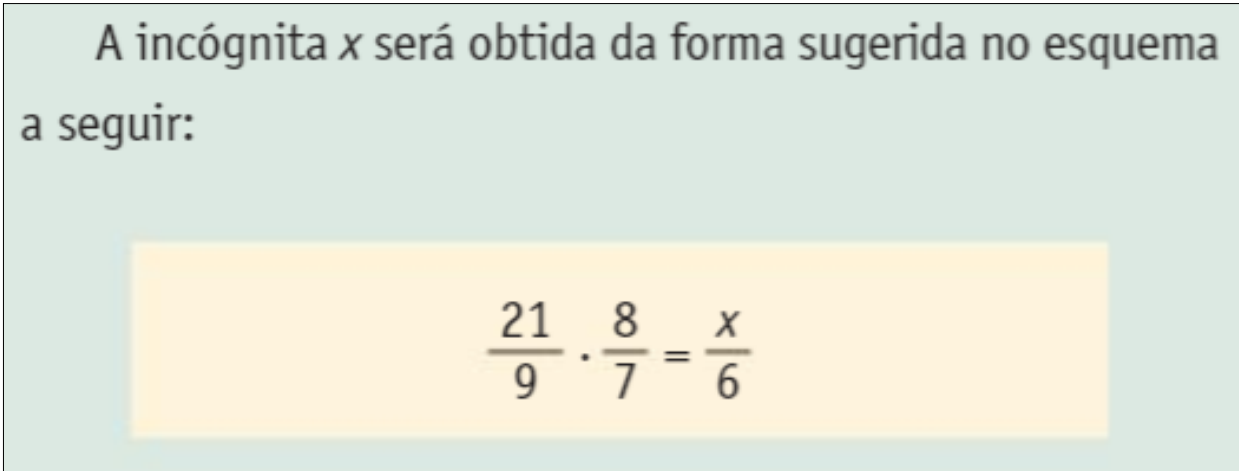

Fonte: Scrivano et al. (2013, p.120).

Ainda nessa unidade, no capítulo de funções, os autores afirmam que "chegamos a uma equação do 2ำ grau. Vamos encontrar os zeros, ou raízes da função, usando a fórmula de Bhaskara" (SCRIVANO et al., 2013, p.155). Então, fazem a apresentação e a aplicação diretas da fórmula.

Figura 12: Apresentação da denominada fórmula de Bhaskara

\section{Fórmula de Bhaskara}

Quando $a x^{2}+b x+c=0,(\mathrm{a} \neq 0)$, temos: $\Delta=b^{2}-4 a c \operatorname{com} x=\frac{-b \pm \sqrt{ } \Delta}{2 a}$.

$\Delta=b^{2}-4 a c=8^{2}-4 \cdot 1 \cdot 15=64-60=4$

$x=\frac{-b \pm \sqrt{ } \Delta}{2 a} \Rightarrow x=\frac{-(-8) \pm \sqrt{4}}{2}$

Então:

$x_{1}=\frac{-(-8)+\sqrt{4}}{2}=\frac{8+2}{2}=5$

e

$x_{2}=\frac{-(-8)-\sqrt{4}}{2}=\frac{8-2}{2}=3$

Fonte: Scrivano et al. (2013, p.155). 
Não há nem mesmo exibição das relações de Girard (soma e produto das raízes), por exemplo, como ferramenta para obtenção das raízes da função ou mesmo para encontrar a equação quando se tem as raízes. Fariam uso, tranquilamente, da fórmula de Bhaskara para demonstrar o motivo de tais relações funcionarem. Afinal, "Explorar novas técnicas ou relações, provar buscando o autoconvencimento e o convencimento dos outros também são competências a serem desenvolvidas" (SALES, 2010, p.131).

Mais adiante, há mais um exemplo de argumentação explicativa. Em uma caixa de texto, os autores informam as regras de arredondamento de números sem dizer por que quando temos os algarismos 4, 3, 2 e 1 ou mesmo 0 , arredonda-se a menor e quando temos 9, 8, 7, 6 e, especialmente, 5 deve-se arredondar a maior.

Figura 13: Sobre arredondamento

\section{Como arredondar números}

Para arredondar números é necessário escolher uma ordem numérica e observar a ordem anterior. Veja os exemplos:

No número 45321 , o negrito no algarismo 5 indica a ordem escolhida. $\mathrm{Na}$ ordem anterior, o algarismo é 3. Nesse caso, o número arredondado será 45000. Isto acontecerá quando o algarismo da ordem anterior for 4, 3, 2, 1 ou o.

No número 45678 o algarismo anterior ao algarismo 5 é o algarismo 6. Nesse caso, o número arredondado será 46000 . Isso acontecerá quando o algarismo da ordem anterior for $9,8,7,6$ ou 5 .

Fonte: Scrivano et al. (2013, p.182)

Segundo Sales (2010), quando não há uma discussão de relações, quando não se justifica, quando não há esclarecimento ou tentativa de convencimento é como se houvesse uma "imposição", uma determinação de verdade, sem espaço para diálogo.

Verificando a unidade da etapa 2, identificamos mais argumentações explicativas. Os autores afirmam "A soma das medidas dos quatro ângulos internos de qualquer quadrilátero é igual a 360" (SCRIVANO et al., 2013, p.307). E, então, fazem uso dessa afirmação para encontrar o ângulo de um exemplo ilustrativo. Mas por que essa soma é sempre $360^{\circ}$ ? Uma justificativa não é colocada. 
No caso específico da geometria, os axiomas, as definições, os teoremas e até mesmo a "tradição" [ações baseadas em afirmações não justificadas] de se fazer de um certo modo como acontece nos níveis do ensino fundamental e médio são, muitas vezes, idéias implícitas. Há muitas afirmações que, usualmente, não são demonstradas nesses níveis de ensino (SALES, 2010, p.99).

Mais adiante, o conteúdo é de análise combinatória. O tratamento dado a ele é bastante reduzido, sendo rara a presença de argumentos, sejam explicativos, sejam justificativos.

Na resolução de um sistema de equações a partir do método da substituição (único método anunciado), quase todos os passos apresentados são típicos de uma argumentação explicativa. Ou seja, é dito como se faz sem dizer por que se faz daquela forma. Apenas em um dos passos é dito que "substitui-se o valor encontrado da incógnita isolada na outra equação. A equação passa a ter uma só incógnita e pode ser resolvida de forma usual" (SCRIVANO et al., 2013, p.313). Nota-se somente nesse passo que a segunda afirmação justifica a primeira.

Figura 14: Passo a passo do uso do método de substituição para sistemas de equações

\begin{tabular}{|c|c|c|c|c|}
\hline \multicolumn{5}{|c|}{$\begin{array}{l}\text { A solução gráfica nem sempre é eficiente para a determinação exata dessas coordenadas. } \\
\text { Muitas vezes, apenas valores aproximados da solução podem ser obtidos. A maneira mais efi- } \\
\text { iente para a resolução de um sistema de equações é o método algébrico. Algebricamente, é } \\
\text { ossível obter os valores exatos das coordenadas desse ponto. Neste capítulo, o método algébrico } \\
\text { scolhido para resolver o sistema é o método de substituição, que será mostrado a seguir. }\end{array}$} \\
\hline \multirow{3}{*}{$\begin{array}{l}3 c+2 p=8,50 \text { [primeira equação] } \\
4 c+p=8 \text { [segunda equação] }\end{array}$} & \multicolumn{2}{|c|}{$3 c+2 p=8,5$} & \multicolumn{2}{|c|}{$p=8-4 c$} \\
\hline & \multirow{2}{*}{\multicolumn{2}{|c|}{$3 c+2(8-4 c)=8,5$}} & \multicolumn{2}{|c|}{$p=8-4 \cdot 1,5$} \\
\hline & & $=8,5$ & $p=8-6$ & \\
\hline $\begin{array}{l}4 c+p=8 \\
p=8-4 c\end{array}$ & $3 c-8 c=8$ & -16 & $p=2$ & 1 \\
\hline $\begin{array}{l}\text { Em uma das equações, isola-se em } \\
\text { um dos membros qualquer uma das } \\
\text { incógnitas. No caso, foi escolhida a } \\
\text { incógnita } p \text { da segunda equação. }\end{array}$ & $\begin{array}{l}c=\frac{7,5}{5} \\
c=1,5\end{array}$ & $\begin{array}{l}\text { Substitui-se o valor encontrado da } \\
\text { incógnita isolada na outra equação. } \\
\text { A equação passa a ter uma só } \\
\text { incógnita e pode ser resolvida } \\
\text { da forma usual. Dessa forma, foi } \\
\text { encontrado o valor da incógnita } c \text {. }\end{array}$ & & $\begin{array}{l}\text { Retorna-se à equação } \\
\text { que apresenta a } \\
\text { incógnita } p \text { isolada } \\
\text { e nela substitui-se a } \\
\text { incógnita } c \text { pelo valor } \\
\text { encontrado. Assim, } \\
\text { calcula-se o valor de } p \text {. }\end{array}$ \\
\hline
\end{tabular}

Fonte: Scrivano et al. (2013, p.313).

No capítulo de geometria analítica, a equação geral da reta é apresentada e dela é extraída a equação reduzida, a partir de um exemplo de aplicação dessas equações. Os autores dizem que "por representar todas as equações de retas" (SCRIVANO et al., 2013, p.315), a 
equação $a x+b y+c=0$ é denominada de equação geral da reta, e sinalizam que $a, b$ e c são seus coeficientes, mas não exploram o significado destes, o que nos conduziu a classificar essa passagem da unidade como tendo argumento sem justificativa.

Nos capítulos da Etapa 3, quando se iniciam os estudos sobre trigonometria, as razões trigonométricas são apresentadas, conforme figura a seguir.

Figura 15: Fórmulas para obtenção do seno, cosseno e tangente

A razão tangente de um ângulo $\hat{A}$ é a razão entre o cateto oposto ao ângulo $A$ e o cateto adjacente ao ângulo $\hat{A}$. No triângulo $A B C$, a tangente pode ser representada pelas seguintes expressões:

$$
\operatorname{tg} A=\frac{a}{b} \quad \text { e } \operatorname{tg} B=\frac{b}{a}
$$

A razão seno de um ângulo $\hat{A}$ é a razão entre o cateto oposto ao ângulo $\hat{A}$ e a hipotenusa do triângulo $A B C$. Nesse triângulo, a razão seno pode ser representada pelas seguintes expressões:

$$
\operatorname{sen} A=\frac{a}{c} \quad \text { e } \operatorname{tg} B=\frac{b}{c}
$$

A razão cosseno de um ângulo $\hat{A}$ é a razão entre o cateto adjacente ao ângulo $\hat{A}$ e a hipotenusa do triângulo retângulo $A B C$. Nesse triângulo, a razão cosseno pode ser representada pelas seguintes expressões:

$$
\cos A=\frac{b}{c} \quad \text { e } \operatorname{tg} B=\frac{a}{c}
$$

Outras razões trigonométricas podem ser obtidas sem necessidade de construção da figura e das respectivas medidas. Os ângulos de $30^{\circ}, 45^{\circ}$ e $60^{\circ}$ são chamados de ângulos notáveis justamente por sua ocorrência em algumas figuras geométricas.

Fonte: Scrivano et al. (2013, p.461).

Quanto ao aspecto argumentativo, não há, por exemplo, uma articulação com o círculo trigonométrico para melhor entendimento dessas três relações que há entre as medidas dos lados de um triângulo retângulo e seus ângulos internos. Não há uso da figura de triângulos semelhantes com ângulos congruentes para mostrar que essa relação se mantém, por exemplo, aproveitando para seguir com uma justificativa. Há apenas a definição acompanhada da 
representação em fórmula matemática. Diante dessa maneira de apresentação de conteúdos, é importante ter em mente que:

Conforme o propósito do ensino, uma aprendizagem que priorize a memorização pode ser suficiente ou não. Por exemplo, se no ensino [...] espera-se que o aluno simplesmente aprenda a manipular e arquivar as regras para responder um elenco de exercícios repetitivos, a compreensão instrumental satisfaz. No entanto, se o objetivo do ensino for fazer com que o aluno aprenda os conceitos matemáticos de modo significativo, entendendo não só o "como", mas também o "porque" dos métodos e regras utilizadas em tais conceitos, promovendo assim, a possibilidade de enfrentar situações novas com sucesso, a compreensão relacional se torna imprescindível" (ATTIE, 2016, p.2261).

Por assim dizer, argumentação justificativa, propiciando uma aprendizagem mais significativa, pode desenvolver o raciocínio, a reflexão e, assim, estar direcionada a uma formação crítica. O que não parece ocorrer com a pura memorização e aplicação de fórmulas.

Seguindo com mais uma passagem do livro, observamos o uso de um gráfico com uma reta e, ao lado, a seguinte afirmação (figura 16):

Figura 16: Obtenção de coeficiente angular a partir de um gráfico

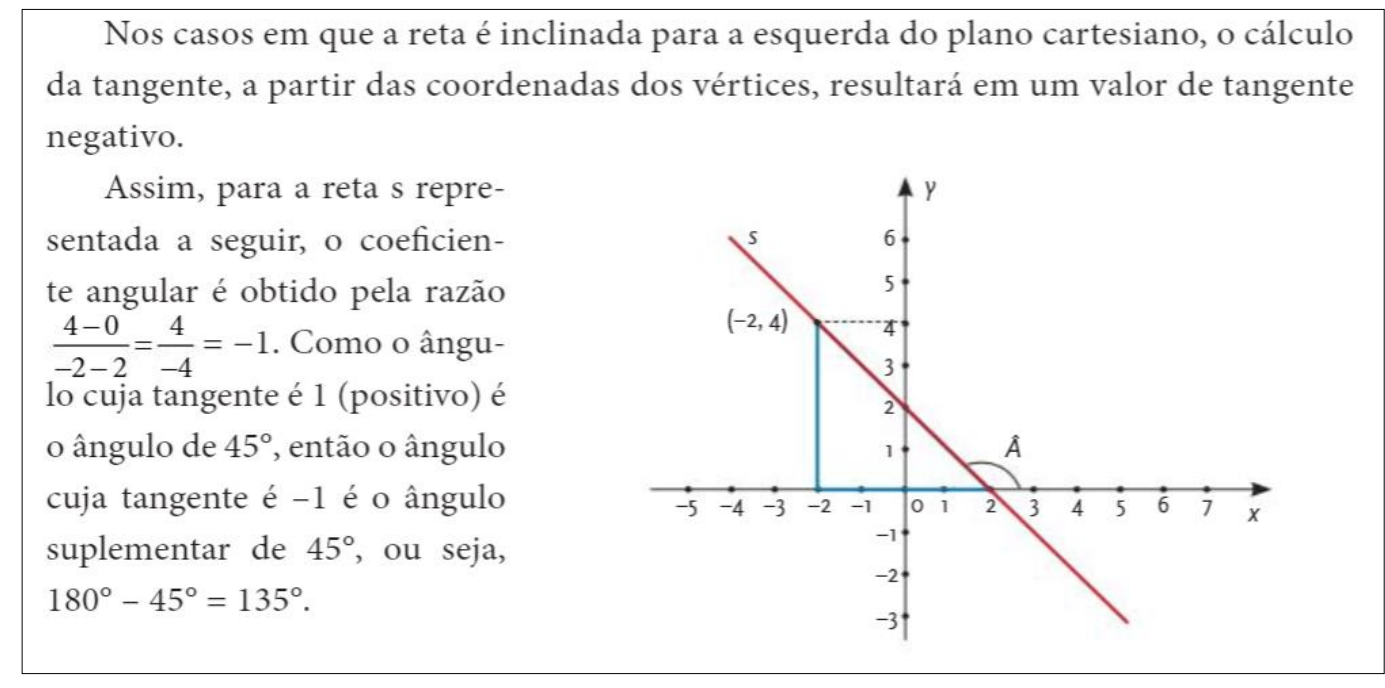

Fonte: Scrivano et al. (2013, p.466).

E concluiram, numa caixa de texto, logo em seguida, que 
Figura 17: Conclusão dos autores sobre as equações reduzidas de duas retas

\section{Conclusão}

Dadas duas retas: $r$ es, cujas equações reduzidas são respectivamente:

$$
y_{r}=m_{r} \cdot x+n_{r} \text { e } y_{s}=m_{s} \cdot x+n_{s},
$$

é possivel provar que se $m_{r}=m_{3}$; as retas são coincidentes ou paralelas; e que, se $m_{r} \cdot m_{s}=-1$, as retas são perpendiculares.

Fonte: Scrivano et al. (2013, p.467).

E, então, há um exemplo de aplicação e pronto. O porquê de tudo isso não é apresentado. Logo, essa passagem do livro também pode ser classificada como um exemplo de argumentação explicativa.

No geral, embora haja predomínio das argumentações explicativas, ressaltamos que as justificativas se fizeram presentes. Ainda que tenha sido pelo critério de seleção estabelecido no edital, conforme relatamos, tal presença é relevante aos propósitos atuais da educação no que tange ao desenvolvimento de autonomia intelectual e pensamento crítico, já que ao justificar um procedimento, por exemplo, pode-se mobilizar o raciocínio e a análise, dentre outras habilidades.

\section{Considerações}

Consideramos necessário, neste ponto, lembrar os conceitos propostos por Balacheff (1988), que afirma que uma argumentação, no caso do ensino de matemática, pode produzir justificativas ou explicações. E é, a partir dessa perspectiva, que utilizamos as expressões argumentação explicativa e argumentação justificativa.

Enquanto uma argumentação explicativa apresenta basicamente o "como fazer", estando, portanto, calcada na utilização de algoritmos e técnicas, sendo legitimada na sala de aula por respostas tais como "é por definição", e tendo como objetivo a mera aplicabilidade das fórmulas, a argumentação justificativa proporciona mais que isso, pois, além de apresentar as maneiras de resolver, mostra também, obrigatoriamente, uma base lógica que justifica o processo que está por trás daquela utilização do algoritmo. Assim, seu objetivo é mais que a 
aplicação da técnica, pois se baseia na necessidade da compreensão do processo envolvido por trás dos elementos empregados.

Considerando esses aspectos, decidimos verificá-los no livro didático destinado à Educação de Jovens e Adultos, sendo relevante ressaltar que para esta modalidade de ensino, a inclusão do livro didático no PNLD é bastante recente e, apesar disto, tem passado por certa descontinuidade. Para o Ensino Médio da EJA, até o momento de produção do presente artigo, o processo de escolha ocorreu apenas no PNLD de 2014, e somente uma coleção foi aprovada. Em circulação, foi dela que selecionamos o livro com componente curricular matemática para um exame em busca de argumentações.

Como pudemos apontar anteriormente, identificamos ao longo das unidades, divididas em três etapas, tanto argumentações explicativas quanto argumentações justificativas. Numa estimativa feita, a partir das argumentações que evidenciamos, percebemos que cerca de $30 \%$ são argumentações justificativas. A presença destas é relevante, independentemente do nível e da modalidade de ensino, pois, como salientamos, elas abrangem os porquês de determinados procedimentos, fórmulas matemáticas e, assim, podem favorecer a reflexão, o raciocínio e a superação do conceito de que a matemática seja algo impossível e que se limita à memorização de procedimentos e fórmulas.

Assim, consideramos que esse predomínio da argumentação explicativa observado no livro didático analisado pode comprometer uma aprendizagem significativa da matemática. Afirmar, por exemplo, que "a soma dos ângulos internos de um quadrilátero é $360^{\circ}$ e não mostrar como se chega a esse resultado revela uma opção pelo tipo de ensino que incentiva a memorização e a repetição e não o uso do raciocínio e a compreensão dos processos envolvidos. Uma maior presença da argumentação justificativa seria desejável para que se possa pensar na promoção de uma educação crítica e cidadã. Mesmo em alguns casos em que a argumentação justificativa aparece, podemos perceber a necessidade de um refinamento em sua apresentação ou mesmo em sua elaboração, como, por exemplo, no cálculo do comprimento da circunferência. Essa re-elaboração poderia levar a um cálculo relativamente fácil para obtenção do número $\pi$, sendo desnecessária, inclusive, a afimação de que a relação entre coomprimento da circunferência, diâmetro e o referido número irracional só se prova a partir de "métodos sofisticados". 


\section{Referências}

ALMEIDA, A; CORSO, A. M. A educação de jovens e adultos: aspectos históricos e sociais. In: CONGRESSO NACIONAL DE EDUCAÇÃO - EDUCERE: formação de professores, complexidade e trabalho docente, 12., 2015, Curitiba. Anais [...] Curitiba: PUCPR, 2015, p.1283-1299. ISSN 21761396.

ATTIE, J. P. Argumentação no ensino de matemática. In: SEMINÁRIO INTERNACIONAL DE ESTUDOS SOBRE DISCURSO E ARGUMENTAÇÃO, 3., 2016, São Cristóvão. Anais [...]. São Cristóvão: Universidade Federal de Sergipe, 2016, p. 2259-2268.

BALACHEFF, N. Une étude des processus de preuve en mathématique chez des élèves de Collège. Thèse d'état - Université Joseph Fourier, Grenoble [France], 1988.

BITTENCOURT, C. M. Livro didático e conhecimento histórico: uma história do saber escolar. 369f. Tese (Doutorado em História Social) - Faculdade de Filosofia, Letras e Ciências Humanas, Universidade de São Paulo, São Paulo, 1993.

BRASIL. Câmara dos Deputados. 56ㅁ Legislatura - 1ํa Sessão Legislativa Ordinária. Legislação. 1939/1945/1966. Disponível em: https://www2.camara.leg.br/atividade-legislativa/legislacao. Acesso em: 27 maio 2019.

BRASIL. [Constituição (1988)]. Constituição da República Federativa do Brasil de 1988. Brasília, DF: Presidência da República, [2019]. Disponível em:

http://www.planalto.gov.br/ccivil_03/constituicao/constituicao.htm. Acesso em: 12 jul 2019.

BRASIL. Lei 9.394, de 20 de dezembro de 1996. Estabelece as Diretrizes e Bases da Educação Nacional. Brasília, DF. 1996.

BRASIL. Secretaria de Educação Fundamental. Parâmetros Curriculares Nacionais: Matemática terceiro e quarto ciclos do ensino fundamental. Brasília, 1998.

BRASIL. Resolução CNE/CBE no 1, de 05 de julho de 2000. Estabelece as Diretrizes Curriculares Nacionais para a Educação de Jovens e Adultos. Brasília, DF, 2000.

BRASIL. Resolução CNE/CBE no 51, de 16 de setembro de 2009. Dispõe sobre o Programa Nacional do Livro Didático para Educação de Jovens e Adultos (PNLD EJA). Brasília, DF, 2009.

BRASIL. Ministério da Educação. FNDE-SECADI. Edital de Convocação 02/2012 - CGPLI. Edital de convocação para o processo de inscrição e avaliação de obras didáticas para o Programa Nacional do Livro Didático para Educação de Jovens e Adultos - PNLD 2014, 2012.

BRASIL. Ministério da Educação. Secretaria de Educação Continuada. Guia dos livros didáticos do PNLD EJA 2014. Natal: EDUFRN, 2014. Disponível em: 
http://www.fnde.gov.br/programas/programas-do-livro/livro-didatico/guia-do-livrodidatico/item/5346-guia-pnld-eja-2014. Acesso em: 20 maio 2019.

BRASIL. COARE/FNDE. Informe 46, de novembro de 2017. Livros Didáticos Destinados à EJA. Brasília, DF. 2017. Disponível em: http://www.fnde.gov.br/index.php/programas/programas-dolivro/pnld/informe-pnld. Acesso em: 20 maio 2019.

BRASIL. COARE/FNDE. Informe 8, de janeiro de 2019. Livros Didáticos Destinados à EJA. Brasília, DF. 2019. Disponível em: http://www.fnde.gov.br/index.php/programas/programas-dolivro/pnld/informe-pnld. Acesso em: 20 maio 2019.

CARRIÃO, A. Marcas do discurso da matemática escolar: uma investigação sobre as interações discursivas nas aulas do ensino médio. 226f. Tese (Doutorado em Educação) - Faculdade de Educação, Universidade Federal de Minas Gerais, Belo Horizonte, 2008.

CARMO, A. B. Argumentação matemática em aulas investigativas de física. 251f. 2015. Tese (Doutorado em Educação) - Faculdade de Educação, Universidade de São Paulo, São Paulo, 2015.

CORDEIRO, E. M.; OLIVEIRA, G. S. As metodologias de ensino predominantes nas salas de aula. In: ENCONTRO DE PESQUISA EM EDUCAÇÃO, 8., 2015, Uberaba. Anais [...]. Uberaba: Universidade de Uberaba, 2015. p.39-55. ISSN: 1809-7901.

FIORENTINI, D. Alguns modos de ver e conceber o ensino da matemática no Brasil. Zetetiké, Campinas, ano 3, n.4, p.01-37, 1995.

FREITAG, B.; COSTA, W.; MOTTA, V. R. O livro didático em questão. São Paulo: Cortez, 1997.

FREITAS, I. Livro didático de história: definições, representações e prescrições de uso. In: OLIVEIRA, M. D.; OLIVEIRA, A. F. B. Livros didáticos de história: escolhas e utilizações. Natal: Editora da UFRN, 2009, p.11-19.

GIL, P. D. B. A história da matemática no fomento de uma cultura de argumentação em sala de aula. 736f. 2013. Tese (Doutorado em Educação) - Instituto de Educação, Universidade do Minho, Braga, Portugal, 2013.

LEITÃO, S. O lugar da argumentação na construção do conhecimento em sala de aula. In: LEITÃO, S.; DAMIANOVIC, M. C. (org.). Argumentação na escola: o conhecimento em construção. Campinas: Pontes Editora, 2011. p.13-46.

MONTEIRO, M. R. C. Práticas avaliativas da capacidade de argumentação matemática de alunos do ensino secundário: um estudo com professores de matemática. 321f. Tese (Doutorado em Educação, Didática da Matemática) - Instituto de Educação, Universidade de Lisboa, Lisboa, Portugal, 2013. 
PIRES, C. M. C. Educação matemática e sua influência no processo de organização e desenvolvimento curricular no Brasil. BOLEMA, Rio Claro, SP, ano 21, n.29, p.13-42, 2008. Disponível em:

http://www.periodicos.rc.biblioteca.unesp.br/index.php/bolema/article/view/1715. Acesso em: 12 jul. 2019.

POMPEU, C. C. Aula de matemática: as relações entre o sujeito e o conhecimento matemático. BOLEMA, Rio Claro, v.27, n.45, p.303-321, 2013. Disponível em: http://www.scielo.br/scielo.php?pid=S0103-636X2013000100015\&script=sci_arttext. Acesso em: 12 jul. 2019.

REGINALDO, B. K. S. Argumentação em atividades investigativas na sala de aula de matemática. 185f. 2012. Dissertação (Mestrado em Educação) - Faculdade de Educação, Universidade Federal de Minas Gerais, Belo Horizonte, 2012.

RODRIGUES, C. B. C. R. C. A argumentação matemática dos alunos do 9o ano de escolaridade no estudo da circunferência. 165f. 2018. Dissertação (Mestrado em Ensino) - Instituto de Educação, Universidade de Lisboa, Lisboa, Portugal, 2018.

SALES, A. Práticas argumentativas no estudo da geometria por acadêmicos de licenciatura em matemática. 243f. 2010. Tese (Doutorado em Educação) - Faculdade de Educação, Universidade Federal de Mato Grosso do Sul, Campo Grande, 2010.

SCRIVANO, C. N. et al. Coleção viver, aprender - ciência, transformação e cotidiano: ciências da natureza e matemática, ensino médio [Educação de Jovens e Adultos]. São Paulo: Global, 2013.

UTSUMI, M. C.; LIMA, R. C. P. Um estudo sobre as atitudes de alunas de pedagogia em relação à matemática. São Paulo: Educação Matemática em Revista, v.24, p.46-54, 2008. Disponível em: http://sbem.iuri0094.hospedagemdesites.ws/revista/index.php/emr/article/view/885. Acesso em: 12 jul. 2019.

Recebido em fevereiro 2020.

Aprovado em agosto 2020. 